\title{
A poética do outro em Niketche: figuras de alteridade na literatura moçambicana
}

\author{
The poetics of the other in "Niketche": \\ figures of otherness in the literature of Mozambique \\ Maiane Pires TIGRE* \\ Universidade Estadual de Santa Cruz (UESC) \\ Isaías Francisco de CARVALHO** \\ Universidade Estadual de Santa Cruz (UESC)
}

\begin{abstract}
RESUMO: Analisa-se a condição da mulher negra moçambicana, no contexto da literatura póscolonial, a partir da obra Niketche: uma história de poligamia (2004), enfocando-se as figuras de alteridade presentes na narrativa. O ponto fulcral da análise reside no estudo da poética do outro, afirmando-se a importância de se narrar a si mesmo ao suplantar o não-dizer do feminino negro. Graças à proeminência dos estudos pós-coloniais, esse Outro permanece em suspenso, ocupando um espaço intervalar, e passa a questionar a história única narrada sobre si. A personagem Rami, velha imagem outrizada, se desconstrói na medida em que uma nova imagem de mulher, parcialmente autorizada, é (re)construída. Trata-se de uma investigação de cunho bibliográfico, fundamentada nos estudos culturais e pós-coloniais.
\end{abstract}

PALAVRAS-CHAVE: Mulher Negra. Alteridade. Pós-colonial.

ABSTRACT: The condition of the black woman in the context of Mozambican postcolonial literature, from the work "Niketche: a story of polygamy" (2004), focusing on the figures of otherness present in the narrative. The focal point of the analysis lies in the study of the poetics of the other, the importance of narrating oneself to overcome the silencing of the black woman. Due to the prominence of postcolonial studies, this Other remains on hold, occupying an "inbetween" space, and starts to question the telling of a single story. Rami, the character that represents the old othered image, deconstructs herself to the extent that a new image of woman, partially empowered, is (re)built. It is an investigation of bibliographical nature, based on cultural and postcolonial studies.

KEYWORDS: Black Woman. Otherness. Post-colonial.

Recebido em 21 de outubro de 2016. Aprovado em 8 de dezembro de 2016.

\footnotetext{
* Mestranda do Programa de Pós-Graduação em Letras: Linguagens e Representações do Departamento de Letras e Artes da Universidade Estadual de Santa Cruz - UESC (Ilhéus, Bahia, Brasil). Bolsista Capes. Email: maiane.tigre@hotmail.com.

** Professor de Literaturas Anglófonas e de Língua Inglesa vinculado aos Programas de Mestrado Profissional em Letras - PROFLETRAS e do Mestrado em Letras: Linguagens e Representações do Departamento de Letras e Artes da Universidade Estadual de Santa Cruz - UESC (Ilhéus, Bahia, Brasil). Doutor em Literatura e Cultura (UFBA). Email: isaiasfcarvalho@gmail.com.
} 


\section{Introdução}

Danço sobre a vida e a morte. Danço sobre a tristeza e a solidão. Piso para o fundo da terra todos os males que me torturam. A dança liberta a mente das preocupações do momento. A dança é uma prece. Por que é que não danças?

Paulina Chiziane, Niketche: uma história de poligamia

No compasso da Niketche, dança do amor e erotismo, a literatura feminina de Paulina Chiziane, primeira escritora moçambicana, invade os espaços proibidos pela tradição, marca o tom e define o ritmo de uma escrita pós-colonial que representa as múltiplas vozes minoritárias daquele país. Chiziane renuncia ao "espaço feminino" da casa e da cozinha para escrever e falar das mazelas do feminino negro sepultadas nas malhas do tempo e nos limites geográficos de Moçambique. O romance Niketche: uma história de poligamia (2004; doravante Niketche) exprime uma (im)possibilidade de retomada dessa fala e do corpo femininos, outrora furtados, perceptível na confissão de Rami: “[...] calar nossas angústias tornou-se a nossa batalha de cada dia.” (CHIZIANE, 2004, p.13).

Para que o feminino negro pudesse falar, era necessária uma literatura afinada com os anseios e problemáticas da subalternidade. A literatura pós-colonial reinscreveu mulheres negras subalternas em narrativas que alavancaram o seu protagonismo. Esse é nosso contexto de emancipação possível, aqui representada pela voz de Paulina Chiziane.

Segundo Stuart Hall (2002, p. 118), o pós-colonial constitui uma tentativa de superação do colonial, ou seja, de reconceitualização da narrativa oficial da colonização, que, por muito tempo, subjugou, explorou e silenciou o Outro. Nesse sentido, a fim de eliminar os equívocos da "história única" (ADICHIE, 2009, online) narrada sobre esse Outro colonizado, Chiziane mergulha no complexo universo da pós-colonialidade e lança-se na escritura do feminino negro outrizado. Com isso, a personagem e narradora Rami, bem como as amantes de Tony, seu marido, são fortes representações da pulsão, do desejo e da poética do Outro, reduto e paisagem de um horizonte (in)finito e intercambiado por figuras de alteridade. 
Com o fito de reempossar à mulher esse direito à fala e ao corpo negro, ou seja, à posse sobre si mesma para vencer a batalha do emudecimento, a obra em tela desconstrói a tradição falocêntrica que preconiza a subalternidade do feminino negro. Nega tabus e interdições e traça um panorama auspicioso - interpretado na voz feminina africana - de liberdade social, cultural e econômica para as mulheres negras. Nesse sentido, este trabalho empreende um estudo de base bibliográfica, fundamentado teoricamente em Gayatri Spivak (1985; 1994; 2010), Homi Bhabha (1998), Stuart Hall (2002), Carvalho (2003; 2010; 2013), Hamilton (1999), Paul Gilroy (2002), Fanon (2008) e Paterson (2007).

Esta pesquisa se propõe a refletir acerca da literatura moçambicana de autoria feminina, em espaços pós-coloniais, nos quais o feminino negro ascende do status de coadjuvante ou figurante para o de personagem principal que narra a sua trajetória de vida política, social e histórica, possibilitando o empoderamento de vozes historicamente silenciadas.

A escolha desse romance e da abordagem específica justifica-se pela relevância da narrativa, diante do recrudescimento da literatura africana, no contexto dos estudos pós-coloniais, além da forte conotação pejorativa destinada à mulher africana, tratada milenarmente como o Outro, cópia imperfeita do homem. Em Niketche, esse Outro é suplantado, dando lugar à construção de sujeitos (mais) agentes política e humanamente capazes de intervenção na representação de si mesmos na condição feminina negra.

\section{O "perigo da história única" sobre as mulheres negras moçambicanas}

A atual controvérsia em torno do termo pós-colonialismo, implica a dissonante natureza da sua teoria e aplicação, disseminando, entre acadêmicos e estudiosos de diversas áreas, polêmicas no campo das correntes pós-modernistas. Em Marginal Returns: The Trouble with Post-Colonial Theory, Russell Jacoby traça a definição do pós-colonial, afirmando que, enquanto “one scholl maintains that 'post-colonial' refers to societies after the onset of colonialism; another restricts the field to the period after the end of legal colonization following World War II" (JACOBY, 1995, p. 30). O autor mencionado, ao referir-se ao pós-colonial, antecipa-se dizendo que se trata de "latest 
catchall term to dazzle the academic mind". Seja como for, o pós-colonial tem estado em toda parte, embora haja controvérsias, tanto sobre sua origem, quanto de suas pretensões. (JACOBY, 1995, p. 30).

Abrimos aqui um parêntese para reafirmar a pertinência do prefixo "pós", conquanto tenha suscitado calorosos debates, quando enxergado a partir de pontos de vista díspares, ao codificar ou descodificar o evento "colonial". A esse respeito, Kwame Anthony Appiah (2010) elabora o estudo analítico Será que o pós- do pós-modernismo é o pós-do pós-colonial?, expondo as bifurcações e semelhanças entre ambos. Para Appiah (2010, p. 7), o "pós" das duas expressões pretende:

[...] abrir um espaço em que se distinga dos outros produtores e produtos - e isto faz-se através da construção e marcação de diferenças." Ademais, o 'pós' do pós-colonialismo, tal qual o do pósmodernismo "[...] desafia as narrativas legitimadoras anteriores. (HAMILTON, 1999, p. 14).

As literaturas dos PALOP (Países Africanos de Língua Oficial Portuguesa) são narrativas pós-coloniais, e também coloniais, a depender do período. Nesse sentido, Hamilton (1999) chama a atenção para o termo colonial: assevera que possui significado flutuante. Há quem afirme que os termos colonial e pós-colonial se restringem às subjetividades históricas e sociais da América Latina, África e Ásia ou vinculam-se aos colonos brancos provenientes do Canadá, Austrália, Nova Zelândia e Estados Unidos.

Nesse jogo de sentidos, Hamilton (1999) aprofunda a discussão concernente à diferença residente na escrita. Alguns estudiosos grafam 'pós-colonial' com traço para consignar o período depois do colonial e a expressão póscolonialismo, sem hífen, indicaria a causalidade com o colonialismo, ou seja, a relação de oposição estabelecida entre este e aquele, sugerindo uma aversão ao regime colonial, mais conhecido como anti-colonialismo. Chiziane ilustra, no trecho a seguir, a justificativa para oposição ao colonial, haja vista que o colonialismo tenciona produzir indivíduos assimilados, pois “[...] o colonizado é cego, destrói o seu eu, assimila o alheio, sem enxergar o próprio umbigo.” (CHIZIANE, 2004, p. 45).

Carvalho (2009), em $O$ narrador pós-colonial, articula as duas entidades, a saber, o narrador pós-moderno e o narrador pós-colonial, buscando caracterizá-las por meio de método comparativo interlocutório. Ao narrador pós-moderno atribui a descentralidade da ação, exímio observador da ação de outrem, enquanto o narrador 
pós-colonial encena a própria experiência ou a de alguém despossuído do direito a fala. Para o autor, o narrador pós-colonial trabalha com o sujeito coletivo e relacional substituindo o eu pelos infinitos "nós", do cordão umbilical da história de uma nação ou de um povo (já que, em português, "nós" tanto pode representar a primeira pessoa do plural quanto o plural de "nó"):

No contexto pós-colonial caribenho, de onde Édouard Glissant fala, e ainda de acordo com suas considerações, o que se necessita é o desenvolvimento de uma poética do 'sujeito', pois há muito os povos dessa região, assim como, de um modo geral, todos os marginalizados, têm sido 'objetificados' ou mesmo 'objetados'. Portanto, o texto deve ser desestabilizado, em acordo com a teoria européia, mas deve sê-lo, na experiência vivida no Caribe, e nessa esfera inclui-se Omeros, principalmente porque o texto deve pertencer a uma realidade comum, e não a um exercício asséptico de intelectuais de gabinete. O 'Nós' coletivo torna-se o lugar do sistema gerativo, e qualquer concepção dogmática de criação literária é uma oposição a essa força do relacional e do comungado. (CARVALHO, 2009, p. 4).

De fato, Carvalho faz uma releitura de Édouard Glissant (1989), ao argumentar que o debate teórico europeu, de teor pós-estruturalista, advoga a desestabilização do texto e do autor. Nessa linha, a poética dos sujeitos subalternizados prevê a desestabilização do texto em prol desses sujeitos, de acordo com o molde ocidental, da experiência do narrador. Todavia, é importante nesse ato situar os sujeitos em sua experiência do pós-colonial.

As literaturas dos PALOP, no contexto da pós-colonialidade, inscrevem esses sujeitos na narrativa, alterando o processo de fabricar a alteridade, o Outro, replicado em vários Outros. Nesse sentido, considera-se a multiplicidade da pós-colonialidade africana a partir das experiências das ex-colônias (portuguesas, em nosso caso): Angola, Cabo-Verde, Guiné-Bissau, Moçambique e São Tomé e Príncipe, sob o ponto de vista histórico e cultural, fraturando o imaginário de uma África unívoca. Desse modo, o hibridismo é um ingrediente imprescindível da pós-colonialidade (HAMILTON, 1999, p. 15).

Em Moçambique, a literatura pós-colonial se afirma nos poemas, romances e autobiografias, em obras cujo teor anticolonialista revela uma acirrada militância em desfavor da norma colonial, da cultura colonizadora. Niketche é um exemplo disso. A linguagem repleta de termos africanos, além das fortes marcas da oralidade, o registro 
dos mitos, da cultura moçambicana e os retratos da subordinação da mulher denotam uma tentativa de superação da literatura colonial, em direção a um movimento de libertação, por intermédio de uma literatura que inaugura a reconstrução identitária de um povo e, por que não dizer, da nação, porquanto deseja (re)viver o seu espaço-mundo pós-colonial:

[...] lobolo no sul, ritos de iniciação no norte. Instituições fortes, incorruptíveis. Resistiram ao colonialismo. Ao cristianismo e ao islamismo. Resistiram à tirania revolucionária. Resistirão sempre. Porque são a essência do povo, a alma do povo. Através delas há um povo que se afirma perante o mundo e mostra que quer viver do seu jeito. (CHIZIANE, 2004, p. 47).

Reescrever a trajetória mítica das mulheres moçambicanas africanas desmistificando o já dito, escrito, a fábula contada, é um desafio, já que “[...] a literatura africana é uma negação dos mitos produzidos na era colonial” (PORTUGAL, 1999, p. 25). Nesse interstício, nasce a literatura feminina de Chiziane, em um contexto de ambivalências. Impera o preconceito, a negligência para com a mulher negra escritora, haja vista que "[...] o acesso ao texto verbal lhes era duas vezes barrado: por serem mulheres e africanas. Encher de palavras o silêncio histórico foi para elas uma árdua e difícil conquista" (PADILHA, 2002, p. 171).

Somente uma literatura pós-colonial atuante para destruir o ciclo de reprodução dessa complexa lógica colonizadora, sugerindo discussões sobre "[...] novas estruturas transregionais, transnacionais, translinguísticas e, como consequência, transculturais" (HAMILTON, 1999, p. 22). Niketche caracteriza-se como emblema nesse contexto, por explorar questões de violência contra o gênero e a cor, entre outras formas de outrização. No contexto da pós-colonialidade, assume status paralelo ao do contexto de colonização. Dito de outro modo, a opressão de gênero converte-se em uma espécie de homogeneização identitária do Outro. O pós-colonial em Niketche descortina as fronteiras invisíveis de outrização ao feminino negro, construindo uma história alternativa, de reinscrição desses outros sujeitos.

Chimamanda Adichie, escritora nigeriana de destaque na atualidade, autora de poemas, contos e romances, em sua participação em um evento livre do TED (TEDx) sobre feminismo, em julho de 2009, proferiu uma palestra com o título $O$ perigo da história única. A escritora, através de um raciocínio dedutivo, narra sua história 
empiricamente e apresenta as diversas narrativas sobrepostas que alinhavam a ideiachave do perigo de uma única história sobre quaisquer que sejam as matérias.

De igual modo, as narrativas hegemônicas se prestam a disseminar representações unilaterais, portanto inverídicas e parciais, do ponto de vista do intelectual palestino, Edward Said, para o qual “[...] o Oriente era quase uma invenção europeia, e fora desde a Antiguidade um lugar de romance, de seres exóticos, de memórias e paisagens obsessivas, de experiências notáveis." (SAID, 1990, p.13). Em sua obra seminal aos estudos pós-coloniais, Orientalismo (1990), o autor apresenta a perspectiva exoticizada acerca do Oriente, divulgada pelo Ocidente na literatura, nas ciências e na mídia, entre outros. O Oriente é traduzido como o Outro do Ocidente, de acordo com o autor, avolumando os estigmas que incidem sobre ele, o que comprovaria a necessidade do colonialismo europeu e confirmaria a história única sobre o Oriente, esse Outro.

Adicchie (2009), nessa mesma linha, revela como o continente africano é bombardeado por olhares altivos e judicantes, uma vez estabelecidos esses ou aqueles prognósticos ocidentalizantes de pessoas que, muitas vezes, nem sequer haviam visitado ou conhecido do lado de dentro. Em certo trecho de sua referida palestra, declara:

[...] mas devido a escritores como Chinua Achebe e Camara Laye eu passei por uma mudança mental em minha percepção da literatura. Eu percebi que pessoas como eu, meninas com a pele da cor de chocolate, cujos cabelos crespos não poderiam formar rabos-de-cavalo, também podiam existir na literatura. Eu comecei a escrever sobre coisas que eu reconhecia. (ADICHIE, 2009, online).

A escritora alerta sobre a tessitura das narrativas culturais que articulam histórias distintas e contínuas à substância vivida, ora impregnadas de preconceitos, ora distorcendo a realidade. Em determinada parte de sua declaração, defende que nossas biografias e culturas são conformadas pela sobreposição de múltiplas histórias (ADICHIE, 2009), reiterando a existência de histórias entrecruzadas, acopladas umas sobre as outras.

A autora relata ainda como acessou a sua voz cultural, eliminando quaisquer resquícios de univocidade assentes na sua fala ou pensamento em relação a concepções diversas, performance que, quando assimilada, produz repetidores de histórias únicas sobre uma categoria de pessoas ou país, obstruindo a atualização de histórias 
alternativas. Percebe-se, no fragmento a seguir, a história única contada por Tony sobre a sua esposa Rami e, por extensão, sobre quase todas as mulheres negras moçambicanas:

Gostaria de dizer-te que és uma grande mulher. Também não posso. As mulheres são sempre pequenas [...] Queria também dizer que confio em ti, mas também não me é permitido. Os homens devem desconfiar sempre das mulheres, e as mulheres devem confiar sempre nos homens. (CHIZIANE, 2004, p. 328).

Nesse particular, a história única de cada dia contada sobre as mulheres de modo geral diz respeito ao complexo de inferioridade da qual são portadoras. Adjetivadas como seres "menores", isto é, limitadas em quase todos os aspectos em relação aos homens, as mulheres são tributárias de uma extensa lista de caracteres pejorativos que as desqualificam perante os homens, situação agravada quando se tratando de mulheres negras.

Paul Gilroy (2001, p. 77), em $O$ atlântico negro, pontua incisivamente sobre a longínqua liberdade feminina das mulheres negras. Educadas de modo inequívoco "[...] apenas para a maternidade, ao passo que a erudição seria domínio exclusivo de uma cidadania masculina esclarecida". Ao refletir sobre a inviolabilidade da raça, Gilroy (2001, p. 76) confere ao homem negro o múnus de guardião e representante da nação, traçando um paralelo entre o poder da pátria e o poder do "supremo patriarca", o cabeça da organização familiar. Segundo o autor, a integridade da raça diz respeito, antes de tudo, à "integridade de seus chefes masculinos de domicílios".

Gilroy (2001, p. 119-120) também cita Hill Collins, ao reafirmar que as tradições ocidentais retomam o pensamento dualista, exemplificado mediante o par cognitivo, dominado por sua outra metade “[...] reprimida e subjugada masculino/feminino, racional/irracional, natureza/cultura, claro/escuro". Rami, esposa de Tony, é o modelo de mulher escrava, de objeto erótico à mãe, de sorte que o estereótipo de mulher trabalhadora e incansável é antiquíssimo, ampliando ainda mais o estigma da mulher negra: recalcada, subordinada, sexualizada, o Outro, metade podre do macho dominante, intelectualmente incapaz.

As mulheres negras moçambicanas "passaram a existir" a partir da literatura pós-colonial de Chiziane, além de, também, tornarem-se reconhecidas por meio dessa literatura. A história única, contada sobre o feminino negro, cedeu lugar à presença de 
histórias diversas e paralelas, narradas por mulheres negras. As vozes femininas negras assumem a fala autoral dentro e fora da trama. Destarte, como não parece mais existir uma História teleológica, é refutável todo tipo de narrativa que pretenda enquadrar a mulher negra em uma tela de pintura, transformando-a em figura inerte e manipulável, retocada por tintas masculinas.

Historicamente compreendidas à luz de uma ideologia machista, vistas por um único lado da narrativa, prescindidas em sua versão sócio-histórica, dissecadas em suas partes mais baixas, as mulheres moçambicanas foram por muito tempo esboçadas pelo olhar do homem negro, traduzidas por uma faceta da realidade, camuflando a autêntica narrativa de vidas femininas, as quais permaneceram presas às percepções coletivas. Entretanto, as vozes femininas negras de Moçambique, silenciadas e amaldiçoadas, no limiar da narrativa, ressoam desemudecidas. Rami rasga o silêncio e fala: "[...] tenho que exercer o meu direito à palavra e dar o exemplo. Primeiro saem os roncos. Ditongos. Sílabas mortas. Fecho os olhos. Quando os abro, as minhas palavras soam como rajadas maciças, demolidoras. É o princípio da tormenta." (CHIZIANE, 2004, p. 319).

Frantz Fanon (2008), já na introdução de Pele negra, máscaras brancas, inscreve o racismo em discussões filosóficas explorando a quintessência do tema. Chega a definir o negro como uma "zona do não ser", um não-homem, porquanto sua existência está confinada nos limites intransponíveis de sua cor. Nessa perspectiva, a história única do feminino negro ocupa a zona da dupla negação. Em primeiro lugar, por não pertencer ao gênero masculino, não-homem. Depois, por ser destituída da cor branca, não-branca, ocupando a zona do não ser duas vezes. A ausência desses dois caracteres no feminino negro é encarada como destrutiva.

Não obstante, nas palavras de Adichie (2009), “[...] quando nós rejeitamos uma única história, quando percebemos que nunca há apenas uma história sobre nenhum lugar, nós reconquistamos um tipo de paraíso". Admitir o reconto e a reescritura dessa história única sobre as mulheres negras moçambicanas reabre portas de acesso a esse paraíso escondido, desvelado pelo Outro em Niketche, metáfora da assunção do feminino negro. 


\section{A poética do Outro}

A abordagem sobre o Outro encontra lugar privilegiado nas literaturas africanas, enfocando de modo singular, critérios de raça, gênero, nacionalidade e religião. É imprescindível reconhecer a própria literatura pós-colonial, de modo especial, a moçambicana, como essa encarnação do Outro, uma vez que abarca em si mesma o projeto de abraçar a diferença, assumindo-se enquanto exceção de uma literatura eurocêntrica e imperialista. A esse respeito, Bhabha descreve:

Este é o momento de distância estética que dá à narrativa uma dupla face que, como o sujeito sul-africano de cor, representa um hibridismo, uma diferença 'interior', um sujeito que habita a borda de uma realidade 'intervalar'. E a inscrição dessa existência fronteiriça habita uma quietude do tempo e uma estranheza de enquadramento que cria a 'imagem' discursiva na encruzilhada entre história e literatura, unindo casa e mundo. (BHABHA, 1998, p. 35).

Nesse sentido, elucidar o conceito de alteridade na literatura depende da focalização dada ao termo, considerando as diversas áreas envolvidas. Carlos Ceia, em seu Dicionário de termos literários (s/d), conceitua o verbete "Alteridade” como “[...] fato ou estado de ser Outro; diferição do sujeito em relação a um outro". De forma mais significativa, alteridade pode ser compreendida como o lugar da diferença cultural ou do reconhecimento do Outro. Fundamenta-se na premissa de que importa traduzir o Outro para conhecer sua alteridade, não mais numa oposição eu/outro, transpondo os limites deste par em constante conflito para a restauração do diálogo, reunindo nessa realidade intersticial, o particular, a casa ao domínio do outro mundo desconhecido.

Janet Paterson, em Pensando a alteridade hoje (2007), enfatiza que a alteridade pode ser abordada sob ângulos distintos, a saber, na psicologia, na filosofia e na literatura, entre outros. Portanto, não se prende a esquemas interpretativos fixos e universalizantes (PATERSON, 2007, p. 14). Nesse diapasão, Hall (2002) discute sobre a mobilidade do significado de outridade, já que a oposição supracitada está sendo paulatinamente reformulada, haja vista o amplo alcance e revisão dos conceitos de identidade e alteridade no panorama atual:

A própria noção de uma identidade cultural idêntica a si mesma, autoproduzida e autônoma, tal como a de uma economia autosuficiente ou de uma comunidade política absolutamente soberana, teve que ser discursivamente construída no 'Outro' ou através dele, 
por um sistema de similaridades e diferenças, pelo jogo da différance e pela tendência que esses significados fixos possuem de oscilar e deslizar. O 'Outro' deixou de ser um termo fixo no espaço e no tempo externo ao sistema de identificação e se tornou uma exterioridade constitutiva. (HALL, 2002, p. 116).

Nessa mesma perspectiva, Ouellet (apud PATERSON, 2007, p. 15) informa que as sociedades ocidentais devem repensar suas perspectivas em torno do tema alteridade. Defende, ainda, a possibilidade de que tais sociedades estejam dispostas a sofrer uma efetiva "alteração" em seus processos cognitivos e ideológicos, nos assuntos que envolvem raça, gênero e identidade. O caráter central dos estudos sobre alteridade, no contexto nacional e transnacional, representa a fronteira e divisa para a recusa do racismo, discriminação, toda ordem de preconceitos, guerras étnicas e políticas (PATERSON, 2007, p. 15). Pensar a alteridade é viver, de fato, a experiência do outro, a reconceitualização do pensamento resulta em um deslocamento necessário do eu, que “[...] não é o Eu colonialista nem o Outro colonizado, mas a perturbadora distância entre os dois que constitui a figura da alteridade colonial" (BHABHA, 1998, p.76).

Paterson (2007) postula também que alteridade e identidade são indissociáveis. Contudo, essa relação é perceptível graças à distinção realizada entre diferença e alteridade. De acordo com Landowski (apud PATERSON, 2007, p. 16), a diferença em si não é fator de exclusão; em contrapartida, torna-se traumática e produz estranheza quando se presta a definir características ou inscrições semânticas e ideológicas, conforme definição a seguir:

Declarar que a mulher é diferente do homem é um fato inconsequente, ou seja, podemos simplesmente dizer também que o homem é diferente da mulher. No entanto, afirmar que a mulher é inferior ao homem e, sendo assim, que não precisa ser educada (como acontece em vários países) é exatamente o processo que Landowski chama de construção da alteridade. É desnecessário dizer que essa construção é arbitrária e reflete a ideologia e o desejo de poder de um grupo dominante. O importante é compreender que o que está em jogo não é a diferença. Nós habitamos um mundo cheio de diferenças. A questão é a forma pela qual interpretamos e lidamos com todas essas diferenças. Daí a necessidade de refletir e reconsiderar o conceito de alteridade. Em última análise, nossa esperança de um mundo melhor reside no respeito por todas as diferenças, e na capacidade renovada de se reconfigurar a questão da identidade. (LANDOWSKI apud PATERSON, 2007, p. 16). 
$\mathrm{Na}$ emergência dos espaços intervalares, sabendo-se que inexiste identidade unívoca, amarrada a apenas uma categoria conceitual - gênero, classe, etnia - concluise que as identidades são multifacetadas e resultado de identificações. Os essencialismos e estereótipos se transformam em amarras obsoletas, típicas de modos de pensamento anteriores a um "pensamento da alteridade" que, por sua vez, necessitam ser revistos, pois “[...] há inúmeros outros fatores embutidos na identidade de uma pessoa, tais como educação, classe social, situação familiar e saúde [...]. Além disso, como afirma Landowski, o outro é uma figura de nós mesmos" (PATERSON, 2007, p.17).

Paradoxalmente, ainda na visão de Paterson (2007, p. 17), a reflexão sobre alteridade contribui para desenvolver uma ética de estar com o outro. Acima de tudo, propõe o deslocamento, tradução e transcendência da distinção nós/eles ou eu/outro, entranhada na subjetividade do indivíduo, na medida em que se opta pelo respeito à heterogeneidade étnica, gênero e classe, entre outros.

Os estudos literários são o palco onde se desenrolam eventos e modos de pensamento que englobam a perspectiva da outridade, de forma mais abrangente que qualquer outra forma artística. Portanto, a literatura é capaz de representar e produzir alteridade, reconhecendo as figuras do outro, de maneira simbólica e complexa, no bojo das narrativas ficcionais, como em Niketche, texto aqui abordado como emblema desse processo. O tecido literário costura as vozes e histórias dissonantes enquanto local onde o encontro se faz presente:

Viver no mundo estranho, encontrar suas ambivalências e ambiguidades encenadas na casa da ficção, ou encontrar sua separação e divisão representadas na obra de arte, é também afirmar um profundo desejo de solidariedade social: "Estou buscando o encontro, quero o encontro... quero o encontro". (BHABHA, 1998, p. 42).

As fronteiras enunciativas do outro, portanto, residem na possibilidade do encontro, enviesado pelo sentimento de solidariedade que une o eu ao outro. Apesar das ambivalências e ambiguidades, o encontro não é somente possível, mas necessário.

\section{Voz e corpo outrizados ou autorizados?}

O subalternizado é o outro heterogêneo, abarcado por um projeto imperialista colonizador do Sujeito Europeu, visando à dominação e outrização do colonizado. Em 
tempo, para compreender o significado de outrização - othering -, pode ser assinalado o conceito postulado por Gayatri Spivak (1985), com o escopo de explicar a representação do "outro" na Índia, na época em que pertencia, como colônia, ao império Britânico, durante o século XIX. Para Carvalho (2003), o termo "outrização" descreve a possibilidade de tradução do verbete othering, do inglês para o português, correspondendo, mas não como sinônimos, em termos conceituais, aos significantes "alteridade" ou "outridade", estes equivalentes à tradução do vocábulo otherness. Cabe aqui mencionar a proposta de tradução do termo outrização, primeiramente empregada, em língua portuguesa, por Carvalho:

Alteridade se trata de um processo que todos os indivíduos experienciam, em termos psicológicos e psicanalíticos, ao passo que os processos de 'outrização' implicam a interdição, a desautorização, a inferiorização, a demonização, o silenciamento e a colonização do Outro. Outrização é, assim, um processo que inclui práticas discursivas que enaltecem uma identidade positiva de um grupo enquanto estigmatiza e rebaixa, em bases violentas, o outro. (CARVALHO, 2003, p. 10).

De fato, Spivak (2010, p. 66), base da caracterização contida na citação acima, sublinha que a historiografia subalternizada é resultado de uma "violência epistêmica" restrita que interdita e inferioriza o feminino por argumentos sustentados em bases epistemológicas. O sujeito subalterno é acusado de obliterado, alargando profusamente o abismo da subalternidade quando nela estão incluídas questões de gênero. Assim, admite-se o sujeito subalterno como duplamente obliterado, ou seja, na absoluta obscuridade, sem fala, aderido a um silêncio inexorável.

O termo othering (outrização), postulado inicialmente por Spivak, no ensaio The Rani of Sirmur, pode também ser compreendido como o falseamento de representações da realidade histórica (SPIVAK, 1985, p. 271). Uma das acepções empregadas pela intelectual indiana para esse conceito diz respeito à ilustrada em uma carta do General inglês, Sir David Ochterlony, para se referir aos nativos: "I see them only possessing all the brutality and purfidy [sic] of the rudest times without the courage and all the depravity and treachery of the modern days without the knowledge of refinement"

\footnotetext{
1 "Eu os vejo como apenas possuidores de toda a brutalidade e perfídia dos tempos mais rudes sem a coragem e toda a depravação e traição dos dias modernos sem a consciência do refinamento." (SPIVAK, 1985 , p. 254-255; tradução nossa).
} 
(SPIVAK, 1985, p. 254-255). Segundo Carvalho (2003), a descrição fornecida por Spivak visa à construção de imagens estereotipadas do outro, declinado mormente como débil, bárbaro, monstruoso, inferior.

Em Niketche, Rami é esse outro, desautorizado, violentado, outrizado pelo olhar e pelo desejo masculino em toda a superfície de seu corpo e fala. Sobre o corpo da negra moçambicana, o homem exerce irrestrito domínio, apossando-se do outro arbitrariamente:

Olho para todas elas. Mulheres cansadas, usadas. Mulheres belas, mulheres feias. Mulheres novas, mulheres velhas. Mulheres vencidas na batalha do amor. Vivas por fora e mortas por dentro, eternas habitantes das trevas. Mas por que se foram embora os nossos maridos, por que nos abandonam depois de muitos anos de convivência? As minhas vizinhas consolam-me com histórias de espantar [...]. Nos olhos de todas nós miragens do marido que se foi e não volta mais. (CHIZIANE, 2004, p. 13).

A voz feminina transgride o silêncio para narrar singulares histórias de vidas, falando por si mesmas, como acontece com a personagem Rami, ao contar a história paralela das mulheres de seu país:

Navego numa viagem ao tempo. Haréns com duas mil esposas. Régulos com quarenta mulheres. Esposas prometidas antes do nascimento. Contratos sociais. Alianças. Prostíbulos. Casamentos de conveniências. Venda das filhas para aumentar a fortuna dos pais e pagar dívidas de jogo. Escravatura sexual. Casamentos aos doze anos. Corro a memória para o princípio dos princípios. No paraíso bantu, Deus criou um Adão. Várias Evas e um harém. (CHIZIANE, 2004, p. $39-40)$.

Às mulheres são impostos modelos de vida desafiadores de uma nova presença colonial, castradora, dominadora agenciada pelos papeis masculinos, definidos na estrutura familiar e regulada pelo sistema patriarcal. A mulher negra moçambicana, como representada em Niketche, é herdeira de um sistema colonial bárbaro que escravizou, estuprou, dominou e assaltou corpos e falas femininas, conforme demonstrado a seguir:

Em algumas regiões do norte, o homem diz: querido amigo, em honra da nossa amizade e para estreitar os laços da nossa fraternidade, dorme com a minha mulher esta noite. No sul, o homem diz: a mulher 
é meu gado, minha fortuna. Deve ser pastada e conduzida com vara curta. (CHIZIANE, 2004, p. 36).

Em Moçambique, predomina a realidade de que as mulheres negras não podem falar e agir deliberadamente, porque foram rasuradas na história. A experiência de usurpação do corpo e da fala da personagem Rami na obra aqui analisada é fronteiriça como a de milhares outras mulheres de sua cor, gênero e etnia, quando seus corpos/falas deixam de pertencer a si mesmos, como interditos, para serem insolentemente acessados, violados e descartados.

Essa situação é explicitada na fala de Luísa, uma das amantes de Tony, esposo de Rami: "Não tenho ilusões. Quer seja esposa ou amante, a mulher é uma camisa que o homem usa e despe. É um lenço de papel, que se rasga e não se emenda. É sapato que se descola e acaba no lixo." (CHIZIANE, 2004, p. 54).

Na cultura moçambicana do norte, o corpo da mulher negra é partilhado pelo marido com outros homens, existindo como produto a ser consumido: “[...] partilha-se mulher com o amigo, com o visitante nobre, com o irmão de circuncisão. Esposa é água que serve ao caminhante, ao visitante. A relação de amor é uma pegada na areia do mar que as ondas apagam. Mas deixam marcas.” (CHIZIANE, 2004, p. 39).

A esse respeito, sobre situação similar, Spivak afirma que “[...] o estupro grupal perpetrado pelos conquistadores é uma celebração metonímica da aquisição territorial" (SPIVAK, 1994, p. 99)². O mesmo se dá com a mulher negra de Moçambique, vítima de um estupro grupal: seu corpo e sua fala adquirem a condição de territórios de outrização, ou seja, de aquisição forçada praticada por figuras masculinas, atualizando a violência ao sujeito emudecido da mulher subalterna.

A poligamia, apesar de não ser legalizada em Moçambique, se transformou em um obstáculo com a aprovação da Lei da Família (Lei no 10/2004), em 2004, regulamentação legislativa que inibe a discriminação no âmbito familiar e luta a favor da igualdade no seio da família (ARTUR; CRUZ; SILVA et al, 2011). Não obstante, as uniões poligâmicas vigoram como uma prática costumeira no cenário moçambicano. No caso em tela, Tony, marido de Rami, tem outras quatro mulheres e vários filhos com cada uma, clandestinamente, podendo ser considerado a metonímia desse estupro grupal perpetrado no bojo da obra Niketche:

\footnotetext{
${ }^{2}$ Tradução nossa.
} 
Poligamia é uma procissão de esposas, cada uma com o seu petisco para alimentar o senhor [...] Poligamia é exército de crianças, muitos meios-irmãos crescendo felizes inocentes, futuros reprodutores dos ideais de poligamia [...] Poligamia é ser mulher e sofrer até reproduzir o ciclo da violência. (CHIZIANE, 2004, p. 91).

As práticas poligâmicas organizam-se em torno de uma estrutura de poder, porque ser polígamo é dominar, na medida em que o destino das mulheres do Sul é serem dominadas. Todavia, em alguns lugares onde a Igreja Católica é mais atuante, a poligamia, enquanto tradição cultural, foi banida, abrindo espaço para uma poligamia clandestina, ilegal: “A prática mostrou que com uma só esposa não se faz grande patriarca. Por isso, os homens deste povo hoje reclamam o estatuto perdido e querem regressar às raízes. Praticam poligamia do tipo ilegal, informal, sem cumprir os devidos mandamentos.” (CHIZIANE, 2004, p. 92). Sabe-se que, apesar da colonização europeia ter sido exercida com base em uma cultura patriarcal altamente opressora para as mulheres, o corpo/fala da mulher negra, em ambos os casos, tornou-se um território de exploração. A economia da devassidão sexual expurgada na paisagem do corpo negro.

O artigo intitulado Quem reivindica a alteridade?, também de Spivak (1994, p. 188), aborda questões em torno do projeto de reconstrução da história ou da criação de "histórias alternativas", o qual inaugura "vozes sempre mutantes sob uma perspectiva alternativa". Aplicando o argumento acima discutido, Spivak endossa que só é possível entender a alteridade, quando essas vozes passam a ser auscultadas em vez de concederem toda a atenção para "os privilégios da elite pós-colonial num mundo neocolonial".

Em última análise, deve-se rejeitar a história única de catástrofe ou negatividade sobre a figura subalternizada para transpor o campo da discriminação. Rami, acreditando na potência do seu corpo e de sua fala, investe contra o seu marido, abandonando-o, assim como todas as suas amantes, de modo que o feminino negro ressurge como instância potencialmente autorizada:

Meu Deus eu sou poderosa eu sinto que posso salvá-lo desta queda. Tenho nas mãos a fórmula mágica. Dizer sim e resgatá-lo. Dizer não e perdê-lo. Mas eu o perdi muito antes de o encontrar. Ignorou-me muito antes de me conhecer.

-Não te posso salvar. Tento salvar-te mas não consigo, não tenho força, sou fraca, não existo, sou mulher. Os homens é que salva as mulheres e não o contrário. 
- Rami!

-O filho é do Levy! (CHIZIANE, 2004, p. 333).

É o que ocorre com a personagem Rami e as outras mulheres negras da obra. Ao viverem uma história de dominação, burlam a dependência simbólica, libertando-se do ideal do dominante e reivindicam sua alteridade. Rami narra vibrante a reviravolta de Ju, uma das amantes de Tony na narrativa: "Há vingança e festa na alma de Ju. Conseguiu seu espaço e agora come os melhores nacos de bife, come moelas de galinha e cabeças de peixe à vontade e sossegada na sombra da bananeira, ela que outrora era coagida a destinar os melhores nacos listados para o homem" (CHIZIANE, 2004, p. $327)$.

Para Spivak (1994, p.188), é vital questionar como as narrativas são plasmadas por elos de poder e fenômenos imbricados nessa produção. A autora se posiciona de modo a incentivar a experiência de "refazer a história", reescrevê-la em substituição àquelas narrativas históricas construídas, por intermédio de relações de poder.

A questão, portanto, consiste em situar a mulher negra não emancipada num espaço descolonizado, uma figura de alteridade que paulatinamente delimita o espaço pós-colonial de sua produção acadêmica e literária. Dona de uma escrita não assimilada, Chiziane vai tecendo o Outro, objeto que se desintegra em vários Outros hierarquicamente, na medida em que também se descobre como esse Outro, Sujeito de histórias, que recusa assimilação. Nesse sentido, refaz a história do feminino negro projetando-o para transformação/deslocamento/desconstrução da voz e do corpo outrizados em prol de uma subjetividade autorizada.

\section{Considerações Finais}

A complexidade do espaço pós-colonial ocupado pelas mulheres negras moçambicanas, em Niketche, situa-se no campo do (in)definível, porquanto a pergunta que arde é: ainda são coloniais ou pós-coloniais? Vigora a exploração e dominação da mulher negra, ao mesmo tempo em que descreve o lugar da sua alteridade. Qualquer discussão extensa sobre a literatura feminina de Chiziane recai na conclusão de que sua escrita pinta sujeitos subalternizados, com o fito de fotografá-los a partir de sua condição (pós)colonial. Todavia, a disjunção e o inconformismo caracterizam essas figuras de alteridade. 
O espaço Moçambicano redefine a virtualidade e o protagonismo do feminino negro, permitindo-lhe existir para além do contexto de exploração sob o corolário patriarcal. A vocalidade pretensiosa da personagem Rami arranca figurações femininas dos escombros das narrativas históricas, expondo-as como ângelus de alteridade, imaginados privilegiadamente no campo da literatura.

Em certo sentido, a pertinência desta pesquisa encontra-se no fato de poder sonorizar as vozes alternativas e desassujeitar o corpo negro. A margem perde sua obrigatoriedade para o feminino negro que invade o centro e o fragmenta em várias partes, divisando o poder da narrativa e da escritura com o homem. A diferença obliterada ganha corpo e atua indisfarçadamente, desconstruindo as estruturas produtoras da subalternidade. A partir disso, o feminino negro em Niketche reivindica insidiosamente a subjetividade de uma história alternativa, assumindo a autenticidade em tom confessional das distintas histórias de vida. Como a história única sobre as mulheres moçambicanas negras não pode ser apagada ou é impossível voltar atrás e mudar o passado, em que pese a força das instituições históricas, a história pode ser revista: "[...] refazer a história envolve uma negociação com as estruturas que produziram o indivíduo como agente da história.” (SPIVAK, 1994, p. 199).

Pensar a alteridade é terreno profícuo para se compreender a diferença, reesignificando-a. Paterson $(2007$, p. 18) chega à conclusão de que “[...] as vozes alternativas estão se tornando mais sonoras e frequentes na literatura". De fato, Chiziane contemplou essa diferença e sonorizou-a com toda a potência a elocução do feminino negro, através de uma narrativa arguta e rica em perspectivas femininas. Representantes dos sujeitos pós-coloniais que continuam a recusar a exploração masculina, essas narradoras reagem, isolada ou organizadamente, negociando a autorização da sua fala e do seu corpo, ao tempo em que reinvidicam o lugar da sua alteridade sem desfazer a história.

\section{REFERÊNCIAS}

ADICHIE, Chimamanda. O perigo da história única. Estados Unidos: TED Talks, Julho, 2009. Palestra apresentada na conferência oficial da TEDGlobal. Disponível em: https://www.ted.com/talks/chimamanda_adichie the_danger_of_a_single_story/transcri pt?language=pt-br. Acesso em: 25 jul. 2015. 
APPIAH, Kwame Anthony. Será o pós em pós-modernismo o pós em pós-colonial? Trad. Maria José Tavares. In: ArtAfrica: Revista eletrônica do Centro de Estudos Comparatistas da Faculdade de Letras da Universidade de Lisboa. Lisboa, 9 out. 2010. Disponível em:

http://artafrica.letras.ulisboa.pt/uploads/docs/2016/04/18/5714df1ec 40c3.pdf. Acesso em: 25 jul. 2015.

ARTHUR, Maria José; CRUZ E SILVA et. al. Lei da Família (1): Antecedentes e contextos da sua aprovação. Revista Outras Vozes, no 35-36, Agosto-Novembro de 2011. Disponível em: http://www.wlsa.org.mz/artigo/lei-da-familia-1-antecedentes-econtextos/. Acesso em: 03 set. 2016.

BHABHA, Homi. O local da cultura. Belo Horizonte: UFMG, 1998.

CEIA, Carlos: s.v. Alteridade. E-dicionário de termos literários (EDTL), coord. de Carlos Ceia, ISBN: 989-20-0088-9. Disponível em: http://www.edtl.com.pt. Acesso em 24 jul. 2015.

CARVALHO, Isaías Francisco de. O narrador pós-colonial. Anais do I CONLIRE Congresso Nacional de Linguagens e Representações: Linguagens e Leituras; UESC Ilhéus, Bahia / 26 outubro, 2009. Disponível em:

http://www.uesc.br/eventos/iconlireanais/iconlire_anais/anais-19.pdf. Acesso em: 21 nov. 2013.

CARVALHO, Isaías Francisco de. Subalternidade e a "alminha brasileira". Interdisciplinar: Revista de Estudos de Lingua e Literatura. Ano V, v. 11, jan/jun 2010, p. 1-10. Itabaiana-SE: Edições Núcleo de Letras/Universidade Federal de Sergipe, 2010.

CARVALHO, Isaías Francisco de. Omeros-Walcott: outrização produtiva; uma poética semiutópica dos encontros culturais. 158f. Dissertação (Mestrado) - Instituto de Letras, Universidade Federal da Bahia, 2003.

CARVALHO, Isaías Francisco de. Omeros e Viva o povo brasileiro: outrização produtiva e identidades diaspóricas no Caribe Estendido. 179 f. 2012. Tese (Doutorado) - Instituto de Letras, Universidade Federal da Bahia. Salvador: UFBA, 2012.

CHIZIANE, Paulina. Niketche: uma história de poligamia. São Paulo: Companhia das Letras, 2004.

FANON, Frantz. Pele negra, máscaras brancas. Tradução de Renato da Silveira. EDUFBA: Salvador, 2008.

GILROY, Paul. O Atlântico Negro: modernidade e dupla consciência. Rio de Janeiro: 34/Universidade Cândido Mendes, 2002. 
GLISSANT, Edouard. Caribbean discourse: selected essays. Translation and introduction J. Michael Dash. Charlottesville and London: University Press of Virginia, 1989, (Caraf Books series).

HALL, Stuart. Que 'negro' é esse na cultura negra? In: Da diáspora: identidades e mediações culturais. Belo Horizonte: Ed. UFMG, 2002.

HAMILTON, Russell. A literatura nos PALOP e a teoria pós-colonial. Revista Via Atlântica - Publicação da Área de Estudos Comparados de Literaturas de Língua Portuguesa, nº 3, São Paulo, 1999.

JACOBY, Russell. Marginal Returns: The Trouble with Post-Colonial Theory. Revista Cover Story - Lingua Franca, September/October, New York, 1995, p. 35-70.

PADILHA, Laura Cavalcante. Novos Pactos, outras ficções: ensaios sobre literatura afro-luso-brasileira. Porto Alegre: EDIPURS, 2002.

PATERSON, Janet M. Pensando o conceito de alteridade hoje. Entrevista concedida por Janet M. Paterson a Sandra Regina Goulart Almeida. Tradução: Alcione da Cunha Silveira. Aletria, jul-dez, v. 16, 2007.

PORTUGAL, Francisco Salinas. Entre Próspero e Caliban - Literaturas africanas de Língua portuguesa. Galiza: Laiovento, 1999.

SAID, Edward W. Orientalismo: o Oriente como invenção do Ocidente. São Paulo: Companhia das Letras, 1990.

SPIVAK, Gayatri Chakravorty. Pode o subalterno falar? Tradução de Sandra Regina Goulart de Almeida et al. Belo Horizonte: Editora UFMG, 2010.

SPIVAK, Gayatri Chakravorty. The Rani of Sirmur: an essay in reading the archives. History and theory. v. 24, n. 3, outubro de 1985. p. 247-72. Disponível em: http://www.jstor.org/pss/2505169. Acesso em: 15 dez. 2010.

SPIVAK, Gayatri. Quem reivindica a alteridade? In: HOLLANDA, Heloisa Buarque de (Org.). Tendências e impasses: o feminismo como crítica da cultura. Rio de Janeiro: Rocco, 1994.

WOODWARD, Kathryn. Identidade e diferença: uma introdução teórica e conceitual. In: SILVA, Tomaz Tadeu da. Identidade e diferença: a perspectiva dos Estudos Culturais. Petrópolis: Vozes, 2000. p. 7-72. 